Article

\title{
Rururban Partnerships: Urban Accessibility and Its Influence on the Stabilization of the Population in Rural Territories (Extremadura, Spain)
}

\author{
José Luis Gurría Gascón (iD) and Ana Nieto Masot* $*$ (D) \\ Department of Art and Territorial Sciences, University of Extremadura, 10071 Cáceres, Spain; jlgurria@unex.es \\ * Correspondence: ananieto@unex.es
}

Received: 22 June 2020; Accepted: 28 July 2020; Published: 30 July 2020

\begin{abstract}
The process of population concentration in cities is a worldwide phenomenon-not yet finished - which has led to a widespread rural exodus and abandonment of rural areas. In Spain it occurred very abruptly from 1960, leaving numerous population centers abandoned in the northern half of the country. It is the so-called "empty Spain". This problem has recently transcended from the local to the European level and has become part of all political agendas such as "the fight against the demographic challenge", which the European Commission will finance in the next programming period 2021-2027. However, retaining the population in rural areas is a very complex problem that is difficult to solve. The aim of this article is to show that a polycentric system of towns, well distributed throughout the territory-as happens in Extremadura-has sufficient capacity to stabilize the population in the rural environment and is a viable and global alternative to the demographic challenge through the rururban partnerships and the integrated territorial investments. This article studies, as an empirical reality and demonstration effect, the autonomous community of Extremadura, an inland region bordering Portugal, in the southwest of the Iberian Peninsula, which has no abandoned nucleus and still maintains $50 \%$ of its population in rural areas, compared to a national average of less than $20 \%$.
\end{abstract}

Keywords: accessibility; GIS; partnerships; population; rural territory; territorial planning

\section{Introduction}

The current process of urban concentration and rural depopulation is due to a territorial organization and a settlement that do not adjust anymore to the current socioeconomic characteristics. In this sense, it could be affirmed that the abandonment of rural areas, especially smaller towns, is a spontaneous adaptation to the thoughtful socioeconomic and technological changes that have occurred especially in recent decades, as well as a logical response from the population to the current demands for quality of life and social well-being. This has led the rural population to concentrate in urban centers and in some regional capitals. This was stated in the Europe 2000 document [1], which already indicated that "European society has therefore become largely an urban society" and that "the urban area becomes a magnet for growth in the region".

Since 1960, Spain has been facing a serious problem of widespread rural depopulation in the northern half of the country, where there are many totally abandoned population centers. As indicated in the Spanish urban agenda [2], "depopulation is fundamentally a territorial problem and one of lack of strategic vision and supra-local development".

Rural depopulation is not just a problem in Spain or in the Mediterranean, it is a burning issue in most EU countries, which is why all the European institutions are currently planning "the fight against the demographic challenge", basically oriented towards aging and rural depopulation. Hernández 
Luque [3], in relation to the reform of the CAP for the period 2021-2027, expresses this concern for the future by stating that "the urgency of problems such as depopulation, aging—or limited access to basic services requires innovative responses and greater synergies".

Spain is institutionally addressing the challenge of rural depopulation, which is currently on the political agendas of all administrations. Thus, among the measures of territorial order proposed by the Senate to face the demographic challenge [4], it is indicated that it is necessary to adopt "measures that promote the concept of 'functional region', by fostering 'regional centrality'". Later, the National Commissioner for the Demographic Challenge [5] makes a clear reference to this issue by indicating that "... also the headwaters, the intermediate cities or the small provincial capitals are basic to achieve the dynamization of the spaces in demographic risk...".

References to cities and the major role they should play in stabilizing the rural population are increasingly frequent in all institutions. Cities have become the essence and fundamental axes of development, the nodes that structure the entire territory into a system of urban or functional areas, delimited according to the size and accessibility of each city.

This project seeks to demonstrate, that a polycentric system of cities, as the one of the case of study, Extremadura, is capable of decentralizing socioeconomic development, correcting territorial differences and stabilizing the rural population. This is indicated in the territorial agenda of the European Union 2020 [6] when it points out that "a polycentric and balanced territorial development of the European Union is a key element for achieving territorial cohesion". In opposition to the depopulation of the "emptied Spain", which mainly characterizes the northern half of the Spanish country, the population of Extremadura has been highly stabilized until the recent economic crisis, even in municipalities with less than 1000 inhabitants. Thus, Extremadura is one of the few autonomous communities in Spain that does not have any abandoned municipality. These characteristics could probably be extended to the southern half of Spain and to a large part of the rest of the Mediterranean countries of the EU.

The development of telecommunications and the competitiveness imposed by globalization have forced to the cities and their functional areas to organize themselves in networks and to become more complementary, generating synergies and much broader and more competitive economic spaces. The European spatial development perspective (ESDP, art. 183) [7] considers these urban networks as diversified development strategies, especially regarding the creation of networks of smaller towns in less densely settled and economically weaker regions or border areas (art. 75, 76 and 99), as the only opportunity to overcome development difficulties. It is about generating greater joint synergies for a more harmonious and balanced territorial development.

Copus [8], in relation to these networks and rural development, points to the option of rural-urban relationships more cooperative, sustainable and with ecological production and consumption chains within their own rural hinterlands.

Since the beginning of the last decade of the 20th century, the EU has implemented rural development programs, with the aim of diversifying activities and stabilizing the rural population. Although these programs have contributed to the diversification of rural incomes and the maintenance of the population, the he most optimal results have been achieved in territories where urban networks have promoted the diversification of activities and employment for their rural environment, as well as the provision of facilities and services. This is essential for the quality of life and well-being that today's society demands. Ultimately, integrated rururban development must be key to stabilizing the rural population.

Accordingly, the network of urban initiatives (RIU) [9], which prepared the work for the integrated sustainable urban development strategies (ISUDS), states that "in synthesis, sustainable urban development should be progressively channeled towards functional urban areas and polycentric urban systems and towards renewed forms of rural-urban cooperation". Subsequently, the Spanish urban agenda [2], "it pursues to connect the urban and rural environments" and "promote maximum interconnection between rural and urban areas", proposing a territorial model that takes into account, 
together with "metropolitan areas, new centralities and functional urban areas where new relationships are generated territorial and agglomeration economies and flows between various municipalities".

This study proposes a topic that has been widely discussed since the 1990s and that has intensified in the last decade, both at the research level and at the political level: a polycentric urban system of small and medium-sized cities which provide employment and services to their rural areas of influence and, because of this, have contributed to the stability of the rural population. Therefore, it starts from a very consolidated approach and, in principle, it could seem evident and not original. However, in spite of that, it is still to be implemented and developed in EU policies and in most European countries. This is due, largely, to the lack of experiences of success and good practices of rururban development and therefore, to the distrust in the success of a possible financing. As Artmann et al. [10] indicate, "rural-urban partnerships are sometimes regarded as a concept with lacking content, because it is difficult to prove the effectiveness or rural-urban partnerships with hard facts".

It is our intention to provide with this work, a case study, the autonomous community of Extremadura, an inland region on the border with Portugal in southwest Spain, which is a reference of good practices and rural experiences for both the EU Rural programs and the OECD [11,12] and with a territorial organization of small and medium-sized cities, well distributed over most of the territory, which provide facilities and services, but above all diversified activities, employment and multisectoral income not only to their inhabitants, but also to those in their rural environment and which have contributed to the stabilization of the population in their functional rural areas.

The ESPON Strategy [13] ensures that "making Europe open and polycentric is the most convenient territorial strategy supporting the competitiveness, social cohesion and sustainability goals. The efficiency and quality of the European territory lies in networking cities of all sizes, from local to global level [ ... ]. The roadmap to make Europe smart, inclusive and sustainable, requires the European territory to become more open and polycentric".

For this purpose, it would be desirable to develop integrated rurban policies and investments and to strengthen the main town of the county in peripheral areas. Although these are recommendations from the European institutions, there is no specific funding or instruments for their implementation. This is stated in the opinion of the European committee of the regions [14] on in "the improvement of the implementation of the territorial agenda of the European Union 2020" (2015/C 195/05), which points out the importance of relations between cities and their areas of influence and calls for a "policy approach" that promotes the creation of functional regions. In addition, the Directorate-General for regional and urban policy of EU in its "Opinion on integrated sustainable urban development for the period 2014-2020" [15]) expressed the possibility of having integrated management tools for this as the integrated territorial investments (ITI), community led local development (CLLD), etc.

For the moment, EU policies continue to consider rural development programs and urban development programs separately.

That is why we intend to continue insisting on the need to articulate and promote a polycentric system of cities with integrated territorial investments, with the certainty that the desired effects will be achieved, as has happened in Extremadura, even without any specific funding.

Throughout this study, first it reviewed the recommendations of the EU and the other European institutions with reference to this issue. Second, the methodology used is described, through the selection of the main small cities in Extremadura and the classification of its rural municipalities according to the distance to these small cities. In addition, third, the relationship between urban accessibility and the demographic dynamics of all population centers will be analyzed, with the idea that less accessibility corresponds to more regressive demographic dynamics and greater depopulation. Subsequently, proposals for spatial planning will be offered and conclusions will be drawn.

\section{European Policy of Urban and Rural Integration}

In this second section, a review is sought of EU policies in relation to polycentrism, partnerships and rurban integration, an approach that is increasingly explicit in the documentation emanating from the various national and European administrations. 
The EU, with a certain delay and sectoral approaches, has been articulating policies and instruments to face, separately, the agrarian problems initially and the urban problems later. This was confirmed at the time by the General Director for regional policy, Dirk Ahner [16], when he said "However, the methods used under LEADER and URBAN were confined to rural and urban environments, but without any real interaction between them". Since then, despite the proliferation of institutional documents, very little progress has been made in urban functional integration policies. This is despite the fact that since the end of the 1990s, scientific and political recommendations for integration between the city and the countryside will follow, especially by the European Commission (EC) and the European Parliament. However, according to Copus [8] "It finds that the evidence of significant benefits for rural areas, from either 'growth pole' policies or more recent 'rural-urban cooperation' initiatives, is scant". Along with the European EDORA Project (European development opportunities for rural areas) [17], also the ROBUST project (Rural-Urban Europe) can be mentioned [18] or the ESPON strategy [13], with which policies in favor of integration between urban and rural areas have been studied and recommended. Furthermore, there are OECD studies [19], as well as others carried out by entities such as the Committee on Regional Development (REGI) of the European Parliament, the European committee of the regions (CoR) or Ministers responsible for spatial planning (CEMAT) in their successive informal meetings $[6,14,20]$. However, there is still no decisive European policy in this regard, possibly because evidence and experiences are lacking.

The agrarian measures were soon reflected in the common agricultural policy (CAP) in view of the problems of the sector. Nonetheless, already in the Single European Act [21] economic and social cohesion was proposed and the environment and rural development began to be discussed, albeit in a very vague manner, this materializing in a communication from the Commission to the Council and Parliament (1988) about "The future of the rural world" [22]. In 1991, the rural development programs (RDPs) were created through the LEADER Approach [23] and later, in 1996, the PRODER program [24] in the Spanish territory.

The "Agenda 2000: For a stronger and wider Union" [25], edited in 1999, modified the CAP and made a specific reference to rural development as "Second Pillar of the CAP". Although the common agricultural policy has been maintained even with modifications, it has tended to further enhance rural development and, since the late 1990s, to greater urban-rural integration, highlighting the essential role that the city should play in its rural environment in all organizations and forums.

As for urban policy, this is even more recent, starting specifically in the Europe 2000 Communication [1]. In this communication, it is pointed out that a more harmonious urban system is necessary, with the impulse of small and medium-sized cities, in order for them to carry out a role of intermediation and bridge between the metropolises and the most depopulated areas, in a clear reference to rural areas. For the first time, there is an indication regarding the integration between the city and the rural environment.

All the above are references that gradually crystallize, first with the Corfu European Council (1994) [26] and then, with the Europe 2000+ Communication [27], where the need for a "systematic strengthening of rural cities" and "the preservation of balance and equity between rural and urban areas" is mentioned. It is done with greater emphasis in the Cork Declaration (1996) [28], about Rural Europe-Perspectives for the Future, in which a determined bet is already made to "reinforce the role of small towns as integral parts of rural areas and key development factors". Given that this objective is stated in point 3, on Diversification, it seems that the city looms as support for diversification of economic and social activity for their rural hinterland, this being an aspect that will take shape at the end of the decade. In the 2nd European Conference on rural development of Salzburg (Austria, 2003) [29], the same theme will continue to be emphasized, indicating in the preamble of its Declaration that "convinced [ ... ] a balanced relationship between the countryside and urban areas". However, they are not only mentioned in documents and actions referring to rural areas, but also in the European territorial planning policy, with the design of the ESDP (1999) [7]. In it, the necessary association between the city and the countryside and an endogenous, diversified and efficient development of rural 
spaces is specified. Furthermore, the ESDP has marked a clear trend towards integration between urban and rural areas, trying to "overcome the outdated dualism between city and countryside" (Art. 65:21) and later insisting that it should be "a re-evaluation of the relationship between city and countryside as a functional, spatial entity with diverse relationships and interdependencies" (Art. 92:25-26). The strategy even sentences that "the future of many rural areas is becoming increasingly related to the development of urban settlements in rural areas" and raises a "polycentric urban system where the small and medium-sized towns and their inter-dependencies form important hubs and links, especially for rural regions". Moreover, it indicates that "the towns in the countryside, therefore, require particular attention in the preparation of integrated rural development strategies" (Art. 93:26) sharing the responsibility for their mutual development. Hildebrand expressed himself in similar terms [30].

In the opinion of the European committee of the regions (CoR) about the European spatial development perspective (ESDP) [31], four areas of action are proposed. One of these areas deals with the intention of creates the partnership between urban and rural areas and the role of the second ones. Moreover, CoR establishes that "a polycentric urban system where the small and medium-sized towns and their inter-dependencies form important hubs and links, especially for rural regions" (C93) and emphasizing that "in rural problem regions only these towns are capable of offering infrastructure and services for economic activities in the region and easing access to the bigger labor markets".

The proposals for integration between the city and the countryside are becoming increasingly explicit and assiduous in all the documentation issued by the EU.

The socioeconomic development of rural territories necessarily involves the generation and diversification of employment and income unrelated to the agrarian sector and in relation to its neighboring cities. In this sense, the Agenda 2000 [25] and the 2nd European Conference on rural development of Salzburg [29] stipulate that it is necessary to "recognize that the development of rural areas can no longer be based on agriculture alone, and that diversification both within and beyond the agricultural sector is indispensable".

In 2004, in the proposal for a council regulation laying down general provisions on the European regional development fund, the European social fund and the cohesion Fund [32], it is stated that "in view of the importance of the urban dimension and the contribution of towns and cities, particularly medium-sized ones, to regional development, greater account should be taken ..." . Furthermore, it is specified that "the assistance shall, appropriately, support urban regeneration particularly as part of regional development and the renewal of rural areas, etc., through economic diversification" (Art. 3.3:25), taking a further step towards the economic endowment and financing of this urban-rural territorial policy, which at this time has not yet been achieved. It also insists on the "reinforcement of links between urban and rural areas" (Art. 9.4:12).

The reflections and recommendations that are established by European Commission in the Third report on economic and social cohesion: A new partnership for cohesion convergence competitiveness cooperation are deeper and more extensive [33]. Thus, in this report, the development of rural areas is directly linked to proximity to their cities "whereas a number of rural areas are suffering from inadequate economic links with neighboring small and medium-sized towns and their economies are often weakening as a result $[\ldots]$ while rural areas where there are no towns of any size are experiencing falling population and a decline in the availability of basic services". Moreover, this same report establishes three types of rural areas according to the extent of their integration into the rest of the economy and their links with large centers of activity:

(1) Areas integrated into the global economy, which are experiencing economic growth;

(2) Intermediate rural areas relatively far from urban centers, but with good transport links and reasonably well-developed infrastructure, which tend to have stable population and to be in the process of diversifying economically;

(3) Isolated rural areas that are sparsely populated and often situated in peripheral areas, far from urban centers and main transport networks. Their population is generally dependent on agriculture 
and in decline, as well as they tend to have an aging population, poor infrastructure endowment, a low level of basic services, low income per head and a poorly qualified work force. Furthermore, these areas are not usually well integrated into the global economy, so there is a need to develop links with towns even if they are relatively far away.

In Leipzig (2007) [34], in The Territorial Agenda of EU, it is stated that "city regions are thereby surrounded by urban centers and rurally characterized areas and rural areas are surrounded by regional centers and small and medium-sized towns. This is what we call urban-rural partnership", which is a concept that the OECD later endorses and promotes [19], linking this whole approach with transport networks, mobility and accessibility, as well as with new forms of territorial governance between cities and their functional rural areas.

In response to the previous Leipzig Conference, the EU (2008-2009) launches the "Green Paper on Territorial Cohesion, the way ahead" [35], in which it points out that "small and medium-sized towns are more important than their size may suggest, providing infrastructure and services that are key to avoiding rural depopulation and urban drift". At the same time, it is emphasized that "regions and cities are the territorial platform where policies get connected and gain added value".

In the territorial agenda 2020 (Gödöllo, 2011) [6] it is pointed out that "we acknowledge the diverse links that urban and rural territories throughout Europe can have with each other, ranging from peri-urban to peripheral rural regions. Urban-rural interdependence should be recognized through integrated governance and planning based on broad partnership [ ... ]. In rural areas, small and medium-sized towns play a crucial role; therefore, it is important to improve the accessibility of urban centers from related rural territories to ensure the necessary availability of job opportunities and services of general interest". Likewise, it is also recognized in this Agenda [6] that "rural, peripheral and sparsely populated territories may need to enhance their accessibility, foster entrepreneurship and build strong local capacities [ ... ]. Special attention may need to be paid to underdeveloped peripheral rural and sparsely populated areas where disadvantaged social groups often suffer from segregation. Territories facing severe depopulation should have long-term solutions to maintain their economic activity by enhancing job creation, attractive living conditions and public services for inhabitants and businesses".

In the Informal Meeting of EU Ministers Responsible for Territorial Cohesion and Urban Matters Letonia with the Riga Declaration (2015) [36], it is stated that:

"2. Small and medium-sized urban areas (SMUAS) fulfil important economic and social functions being centers for jobs, public and private services, nodes of local transport, etc. 3. SMUAS are, therefore, essential to avoid rural depopulation and urban drift, promoting more balanced overall regional development. Yet they also contribute to development of metropolitan areas being connected in a polycentric network".

The opinion of the European committee of the regions [14] recognizes that "the effective functioning of small and medium-sized towns and the diversification of rural economies are essential steps towards fully implementing the territorial agenda" asserting that "they play an active role in ensuring well-being and prosperity to the inhabitants of surrounding rural areas because they are centers for employment, services, local transport hubs and guide growing transport demand. They therefore play a role in limiting depopulation of urban and rural areas".

In the CORK 2.0 Declaration "A better life in rural areas" $(2016,5)$ [37], the European Union recognizes that "EU support should strengthen rural-urban linkages and align the sustainable development of both rural and urban areas".

In the Pact of Amsterdam [38], the report urban agenda for the EU is drafted and indicates that "a growing number of urban challenges are of a local nature, but require a wider territorial solution (including urban-rural linkage) and cooperation within functional urban areas [ ... ] urban authorities therefore need to cooperate within their functional areas and with their surrounding regions, connecting and reinforcing territorial and urban policies". 
Finally, in the Opinion of the European committee of the regions (127th Plenary Session, 2018) [20] it is requested that "the integrated territorial investments (ITI) approach should be more fully exploited beyond urban areas, where it is most frequently used now, and implemented more widely in rural and functional areas", although a multilevel governance framework is lacking.

In Spain, as in most European countries, these recommendations and agreements have not been taken into account, despite the fact that the competent Ministries have included it in different documents, as in the cited Spanish urban agenda [2], but with little result.

In the case of Extremadura (study area of this work), the role of the city in rural development is only mentioned in the Territorial Study of Extremadura II [39], where it is stipulated that "the balance and viability of rural areas is basically conditioned by the dynamism of medium-sized cities that must constitute an authentic interrelated urban framework that allows the integration of these rural areas with the neuralgic nodes of the urban system and with the main areas of activity and development of the autonomous community".

More specifically, the Government of Extremadura pronounces itself, through the Ministry of the Environment and Countryside, Agrarian Policies and Territory [40], that mentions the Coworking and Networking Rural-urban initiatives "with the purpose of advancing a territorial strategic vision on the consideration of rural-urban spaces as a single geographic space and applying solutions adapted to the needs of both on the same vision on them".

All are proposals and initiatives that, however, have not had sufficient instruments or applicability for optimal development. In any case, practically from the beginning of the autonomic phase (early 1980s) the regional government of Extremadura undertook a process of decentralization of administrative, facilities, services and productive and social infrastructures towards the main cities. This has contributed to their empowerment as county seats, their development and that of their rural environments, relying on the improvement of road infrastructure and a balanced territorial distribution of cities. With this, it has been possible to stop the emigration bleeding and stabilize the rural population to a great extent [41].

Subsequently, in Law 11/2018, of 21 December, on "Territorial planning and sustainable urban planning of Extremadura" (BOE, 35, 9 February 2019) [42], it is indicated that "finding the balance between rural and urban has been the center of the policies for the regional government of Extremadura since its constitution". Undoubtedly, an important effort has been made in the decentralization of facilities and services to the main cities, although there are still extensive peripheral areas, very isolated and inaccessible, without county seats in some cases and, in others, with poorly developed towns in backward environments with regressive demographic dynamics. In any case, as in the rest of Spain, a decided urban-rural comprehensive development policy is lacking, which has sought to articulate in the Territorial Strategy for the Demographic Challenge and Territorial Balance in Extremadura, already proposed in the CES Report [41].

\section{Materials and Methods}

As discussed in the introduction, cities are the axes of economic and social life, but increasingly rapid changes, especially technological ones, have caused disparate transformations in the urban system and rururban relations. Thus, Copus [8] study about "functional region failure" and new theoretical trends, some still incipient, which do not have the corresponding support, either practical or applied in European policies and programs. While in agreement with Copus [8], it must be borne in mind that in regions such as Extremadura and in other areas and countries of Southern Europe, traditionally agrarian and more backward, a traditional urban system still prevails with a set of small and medium-sized cities poorly hierarchized and disorganized in permanent competition and, therefore, quite isolated. However, these areas structure their respective territories or functional areas, although not the regional space as they are not organized through cooperation or complementary networks. In any case, they have formed a very stable, rigid and unalterable structure for decades, without the ability to adapt to the changes and transformations that are taking place on a global 
scale. As Pillet [43] states, the Spanish urban system, although it was reorganized, presents a poor hierarchization, is unbalanced and has serious difficulties for territorial structuring.

From this perspective, it is difficult for cities to radiate development to their rural areas, but they make them participants in their own development, as they need the labor reserve of this rural environment. Thus, the urban areas collaborate and cooperate with their respective functional areas with a diversified offer of employment unrelated to the agricultural sector and with the generation of a system of complementary multi sectoral incomes that allow a decent standard of living for the rural population. Consequently, rural population is also endowed with proximity facilities and services, stabilizing its population and promoting new rural dynamics.

In Extremadura, cities and their functional areas form a well distributed (although not organized) inherited polycentric system throughout most of the territory. This has allowed the stabilization of their population from 1980 or 1990 to 2012, at which time the crisis reached its greatest impact and reversed the previous trend.

In this and other Spanish regions, since the 80s of the last century, a set of interactions was generated between cities and their rural environments that are not normalized or organized, nor do they depend on specific policies or financing, so they are spontaneous and depend on personal decisions. As Berdegué and Meynard state [44], "functional territories are [ ... ] social constructions, that is, spaces that emerge and acquire identity from the life and concrete activity of social actors over time".

This urban system articulates functional areas that are not very dynamic, but very open. In some cases, the rural population decided to migrate to the cities and, in other cases, it was integrated into urban development through increasing mobility, highly changing and inherent in modern-day society. As Velázquez and Estebaranz say [45], "it is possible to speak of a relocation of the rural population, since the most isolated rural areas are emptying out while a concentration of this population is taking place in those closest to the urban centers".

The general hypothesis of this study (see Figure 1) is based on the fact that the rural stability of Extremadura is mainly due to a territorial organization formed by a polycentric system of cities well distributed in most of the regional territory that provide facilities and services and, above all, diversified activities, employment and multi sectoral incomes not only to its inhabitants, but also to those of their rural environments, contributing to the stabilization of their rural functional areas. It is referred to in the graph as urban accessibility and demographic dynamism.

This more generic hypothesis contains two other more specific ones, according to its content: urban system and accessibility.

(a) The first hypothesis is based on the consideration that Extremadura has a system of cities well distributed throughout the territory, forming a polycentric urban system. To respond to this hypothesis, the main cities of the region have been selected, those with more than 10,000 inhabitants, which according to the criteria of the National statistics institute (INE) are the nuclei considered to be urban in Spain. However, in addition, resorting to the evolution of the population, they are the only nuclei that present a positive demographic trend throughout the 20 th century until very recently. They are located in the most developed areas with population densities around the national averages. All the municipalities below this threshold, on the other hand, have a negative evolution. 


\section{METHODOLOGY}
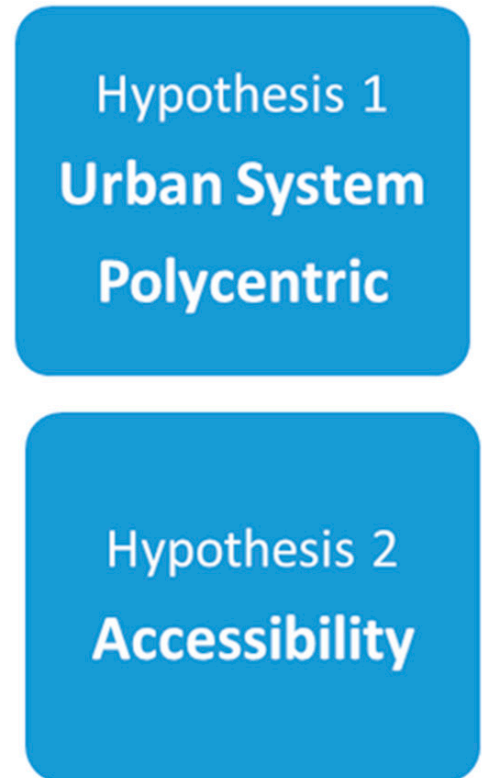
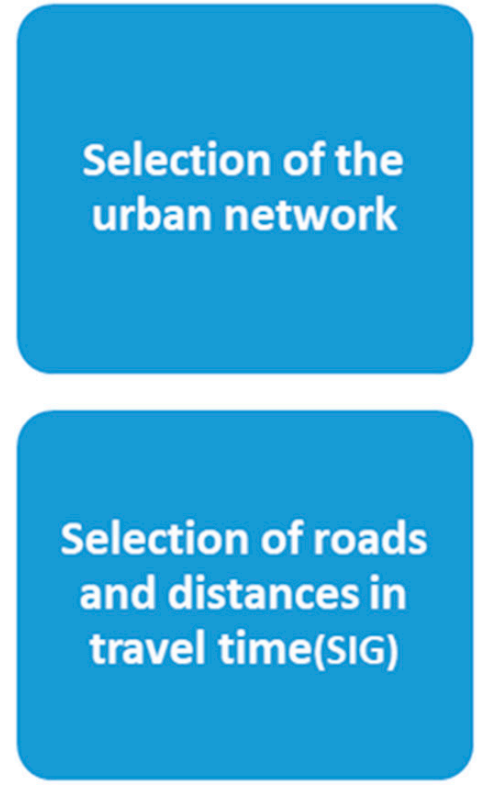

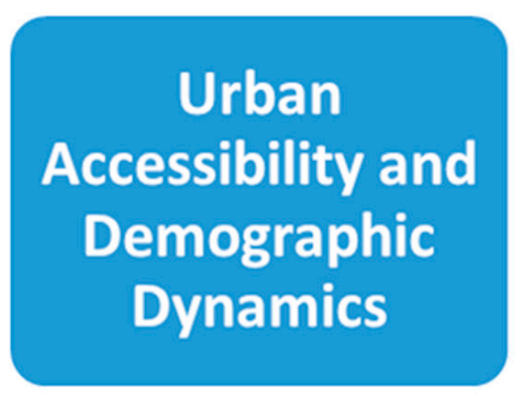

Figure 1. Methodology and hypothesis. Source: the authors.

Although population volume is often used to establish urban rank and hierarchy, since population size is an important variable, it cannot be an exclusive or definitive criterion, due to the diversity of the territorial structures of the Spanish population. As Precedo indicates [46] "a Galician settlement with a thousand inhabitants can achieve the same organizing function as an Andalusian town with more than 10,000 inhabitants". Other authors have resorted to market share, trade as the most characteristic activity, administrative services, public transport concessions, etc., and, in the Report on Large Cities in Spain (2001), the use of various criteria or variables together with that referring to the population is recommended.

In the case of Extremadura, Sánchez Zabala [47] applied a multivariate analysis and Arenal-Clave, in the System of Cities of Extremadura [48], initially classifies urban settlements according to their population, but also in relation to a synthetic index of functionality, which is determined by public and private services and wholesale commercial distribution. The results of these studies could have been used, but the time that has passed leads us to adopt the decision to consider the commercial areas together with the population variable, since they are a very distinctive urban indicator. Only cities with a definite urban rank are able to articulate the system of commercial areas that, in short, come to be functional areas.

For this, it has been decided to use the main cities in the region according to the Socioeconomic Atlas of Extremadura 2019 [49], from the Institute of Statistics of Extremadura. This document dedicates his fourth volume to the commercial areas in the region with enough territorial precision. They are 12 small cities than 10,000 inhabitants, and according to SNI (Statistic National Institute) criteria are considered as urban. Furthermore, they are the only municipalities that show a positive demographic trend throughout the 20th century until very recently. These are located in the most developed areas and with population densities around the national averages. Municipalities below this threshold, on the contrary, have a negative evolution. In Extremadura, there are only two cities that have little more than 10,000 inhabitants (Olivenza and Villafranca de los Barros) and that are not the head of commercial areas according to the Socioeconomic Atlas of Extremadura 2019 [49]. This is because Olivenza is located a few kilometers from the main city of Extremadura, Badajoz and other small cities 
as Villafranca de los Barros, Almendralejo and Zafra. Therefore, Olivenza is strangled and have not been able to develop its own commercial area. Moreover, so it has not been added as small cities of this analysis. In the opposite case, Trujillo appears which has less than 10,000 inhabitants, but has an extensive traditional commercial area due to its geographic location. Moreover, therefore, in this case, Trujillo has been added to this analysis as a small city.

(b) In the second specific hypothesis (Figure 1), which concerns accessibility, it is assumed that urban areas are articulated according to distance and the transport system and accessibility, with an influence that is degraded according to the time and resources invested in travel.

To test the hypothesis, that is, that the urban areas are articulated according to distance and the transport system, with an influence that is degrading according to time and the resources invested in travel, that is, depending on accessibility, the national road map (from the Ministry of transport, mobility and urban agenda) and the road map of the regional government have been used. It seems reasonable that this road network is that maintains the weight of current mobility and rururban interactions. With the twelve urban centers, the minimum travel times in minutes (impedance) have been obtained from each of the remaining 376 municipalities in the region to the closest city among the twelve ones selected following methodologies already used in previous work [50].

It was determined to calculate the time taken from the rural municipalities (less than 10,000 inhabitants) to the 12 small cities. For that, it was necessary to transform the polygonal layer of the municipalities, without taking into account those disseminated, to a dot layer that represent the centroids to calculate, later, their distance to the closest urban center (using the vertices generated). It is necessary to note that the study of accessibility is based on graph theory (these are a collection of nodes) [51,52]. The nodes correspond to the centroids of the population centers, which are connected by edges that are all communication paths. Thus, it is possible to know which node is attached to each edge to calculate the travel time between both nodes. Considering this, the minimum travel time of each population rural center to the nearest point of the urban ones are calculated in this paper. For this, it is necessary to know the hierarchy of the network and rely on impedance since it is a fundamental element in the study of accessibility [53]. The impedance is obtained in minutes and it is the minimum time for a vehicle (in this case, a car) from a population rural center to the nearest urban center. It is then obtained with network analyst tools from a GIS (closest facility). Subsequently, the IDW (inverse distance weight) method was used to capture the minimum travel time on a map, which allows interpolating cell values by combining a set of points to determine the inverse distance of these values [50,54,55].

Then, three ranges of municipalities have been established: those closest to the small cities (with a travel time of less than $15 \mathrm{~min}$ ), those located between 15 and $30 \mathrm{~min}$ and the most remote and peripheral (with more than 30 min of displacement). Other studies and even the department for regional and urban regional and urban policy (DG REGIO), which is based on OECD studies, reach up to $60 \mathrm{~min}$ and Reig the alt. [56] reduces it for Spain to $45 \mathrm{~min}$, since at the national level, if it is reduced further, most of the population would be in a situation of inaccessibility.

When descending to a regional scale, the territorial organization is very diverse, in such a way that in this region the influence of small cities or simple county seats is very small, sometimes barely exceeding $15 \mathrm{~min}$, which is why we have estimated $30 \mathrm{~min}$ as the maximum limit for rururban interrelations. On the other hand, this region does not have the highway system that exists in other Spanish or European regions and, although it has an acceptable road system (average of $95 \mathrm{~km} / \mathrm{h}$ ), the 60 min journey time (even the 45 one) seems to us to be very excessive, especially for some health and education services. In any case, it will be possible to verify if the decision is correct or not when comparing the demographic variables between the ranges of municipalities and when ascertaining the volume of population within this radius.

Finally, in the discussion section, it is intended to insert a proposal to integrate most the regional population in the maximum environment of $30 \mathrm{~min}$ of travel. 


\section{Results}

\subsection{Urban Polycentrism in Rural Areas}

The initial result has been the twelve cities that appear in Figure 2. This model basically coincides, although with small variations, with the results obtained by Sánchez Zabala [47] and its multivariate analysis and by Arenal-Clave [48], who used other criteria, as mentioned. This demonstrates the strength of the urban system, its territorial roots and its temporary stability. These are small and medium-sized cities in which the service sector prevails, highlighting commercial activity and transport, which fits into the schemes proposed by different authors for quite some time for other areas of Spain. Estébanez and Martín Lou [57] state that "commercial and service connections between centers are what determine a system of central places, especially in regions with a dominant agrarian economy". Precedo [46] indicates that "there is a relationship between economic development and the tertiary level of cities [... ] especially in small cities".

Despite the elapsed time, according to previous references, the characterization of small cities in the region has remained practically unchanged. The main cities, coincide with the largest populations and with the most developed and extensive functional areas, are also a temporal constant. This network, which is identical in all the studies mentioned since 1990 despite applying different criteria and techniques, is formed by the two provincial capitals (Badajoz and Cáceres), which would occupy the highest rank (coincide with the range of population between 60,000 and 150,000 inhabitants); the autonomous capital (Mérida) and Plasencia, in a second rank (range from 40,000 to 60,000 inhabitants); and the rest, in a third rank: Coria and Navalmoral, which flank Plasencia, forming the northern axis; Trujillo, as a subarea of Cáceres; in the central axis of Las Vegas del Guadiana, Montijo, Don Benito and Villanueva de la Serena; and, further south, Almendralejo and Zafra (range from 10,000 to 40,000 inhabitants).

In the map, the two essential factors to explain the location of the small cities and their consequent development are represented; these are the topography and the system of the elementary main roads (national main roads only).

In this sense, it should be noted that all the small cities (except Cáceres and Trujillo) are located in the sedimentary basins, which are historically the most productive especially because of their irrigation in the middle of the last century. They are the irrigated areas in the north of the region (in the tributaries of the right bank of the Tagus River) and in the center (in the plains of the Guadiana River) that extend south through the sedimentary basin of Tierra de Barros. At the same time as they were irrigated, their productions were linked to agribusiness, achieving the highest levels of development and population density in the region, which led to a more progressive demographic dynamic and the stabilization of the rural population in their respective areas of influence.

In a traditionally agrarian region like Extremadura, the population has tended to be concentrated in the most productive agrarian areas. This is also verified by Arenal-Clave [48], which indicates that "the organization and arrangement of the constituent elements of the urban system are totally related to the spatial organization of the agrarian productive base". 
Relief, main roads and 12 small cities of Extremadura
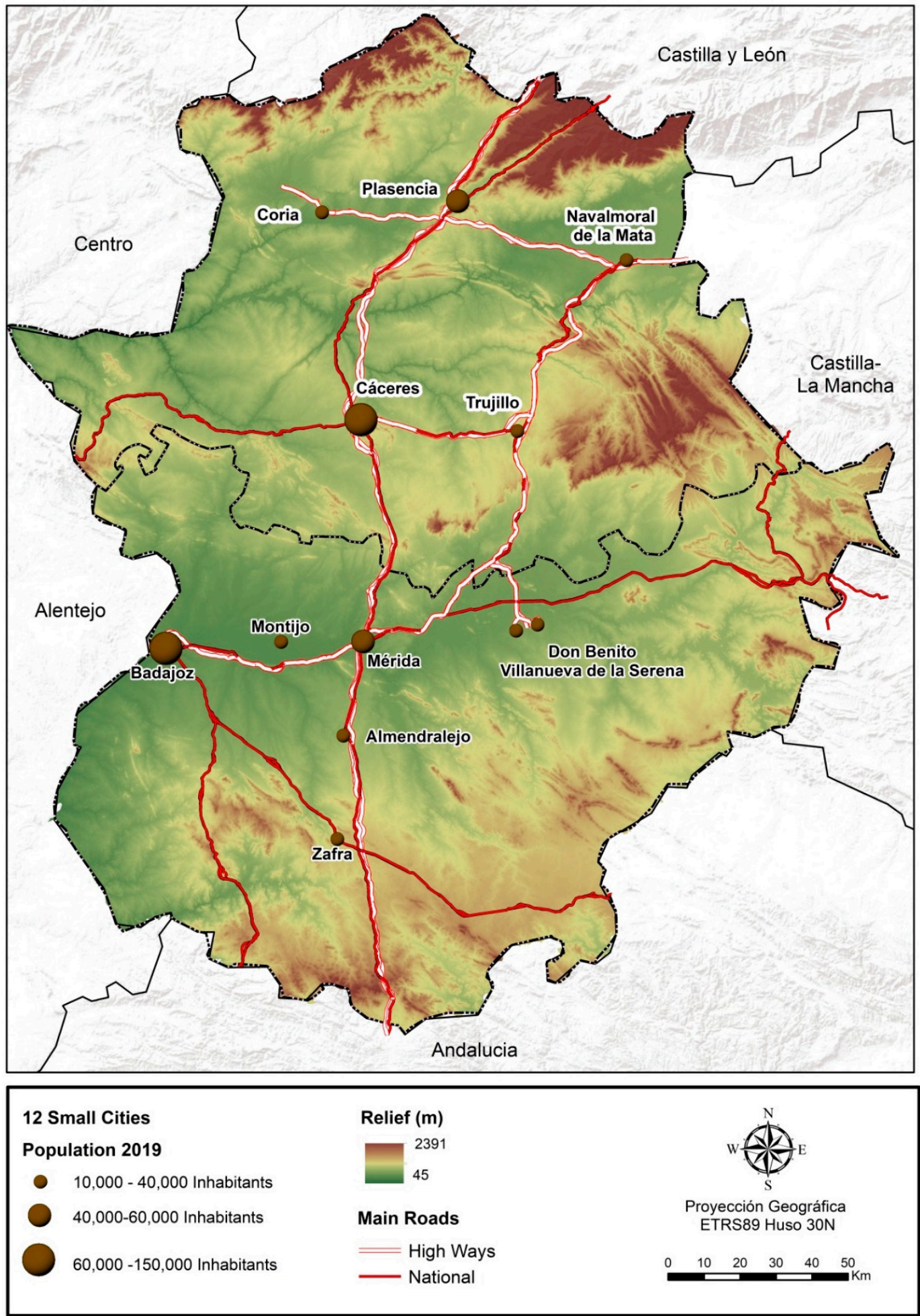

Figure 2. Relief, main roads and 12 small cities of Extremadura. Source: the authors, based on the National Geographic Institute (NGI) and Atlas of Extremadura 2019.

The second factor to explain this location is the transport system, especially the A-66 main road (Sevilla-Gijón), which crosses the region in a north-south direction and the A-5 main road (Madrid-Lisbon), with a northeast direction, due to its importance in communications, in the generation of activities and employment and in the structuring of the regional territory. All the small cities of 
the network in the region are located around the two mentioned main roads, except Coria and Don Benito-Villanueva de La Serena, although they are connected to them through two other regional main roads (EX-A1 and EX-A2). Thus, a polycentric urban system is generated, although with a very central extension in the region made up of two transversal axes along the two large sedimentary basins (Tagus River and Guadiana River-Tierra de Barros) and a north-south longitudinal axis that crosses them and communicates them. Along with these more developed areas, there are quite isolated and inaccessible peripheral areas, both due to the distance to the main cities and due to deficiencies in the transport system, with population densities of less than 10 inhabitants per $\mathrm{km}^{2}$. These are the most backward rural areas with the lowest socioeconomic development and with the most regressive demographic behavior, which shows that, in fact, there is a clear correlation between the distance to the closest cities, urban accessibility and socioeconomic development, what is supported by the European Commission in the ESDP [7]. These are areas in which an agrarian economy persists with adverse factors such as those derived from the relief (mountainous areas of the Central System, to the north; Montes de Toledo, to the east; and Sierra Morena, to the south; or riparian areas because of the deep recess of the Tagus River and its entire dense subsidiary river network). In other cases, these are historical factors, as the case of the Spanish-Portuguese border (to the west), which has acted as an impassable and rigid barrier and repelled infrastructure and investment on both sides.

\subsection{Urban Accessibility and Stabilization of the Rural Population}

Urban influence is gradually degrading until it disappears with distance and travel times for reasons of efficiency and cost. The different areas of influence are spontaneously delimited and conform naturally depending on the urban range and accessibility of each small city. To verify it and as previously mentioned, three ranges were established, with all the municipalities in the region, delimited according to the travel time to the closest city among the twelve selected (less than $15 \mathrm{~min}$, from 15 to 30 and more than 30). The objective is to obtain databases and detect to what extent small cities are influencing the stability of the population in rural areas, which is only possible through the diversification of activities, employment and income, and ultimately, through the decentralization of territorial development (Figure 3). 


\section{Accessibility to Urban Network of Extremadura}

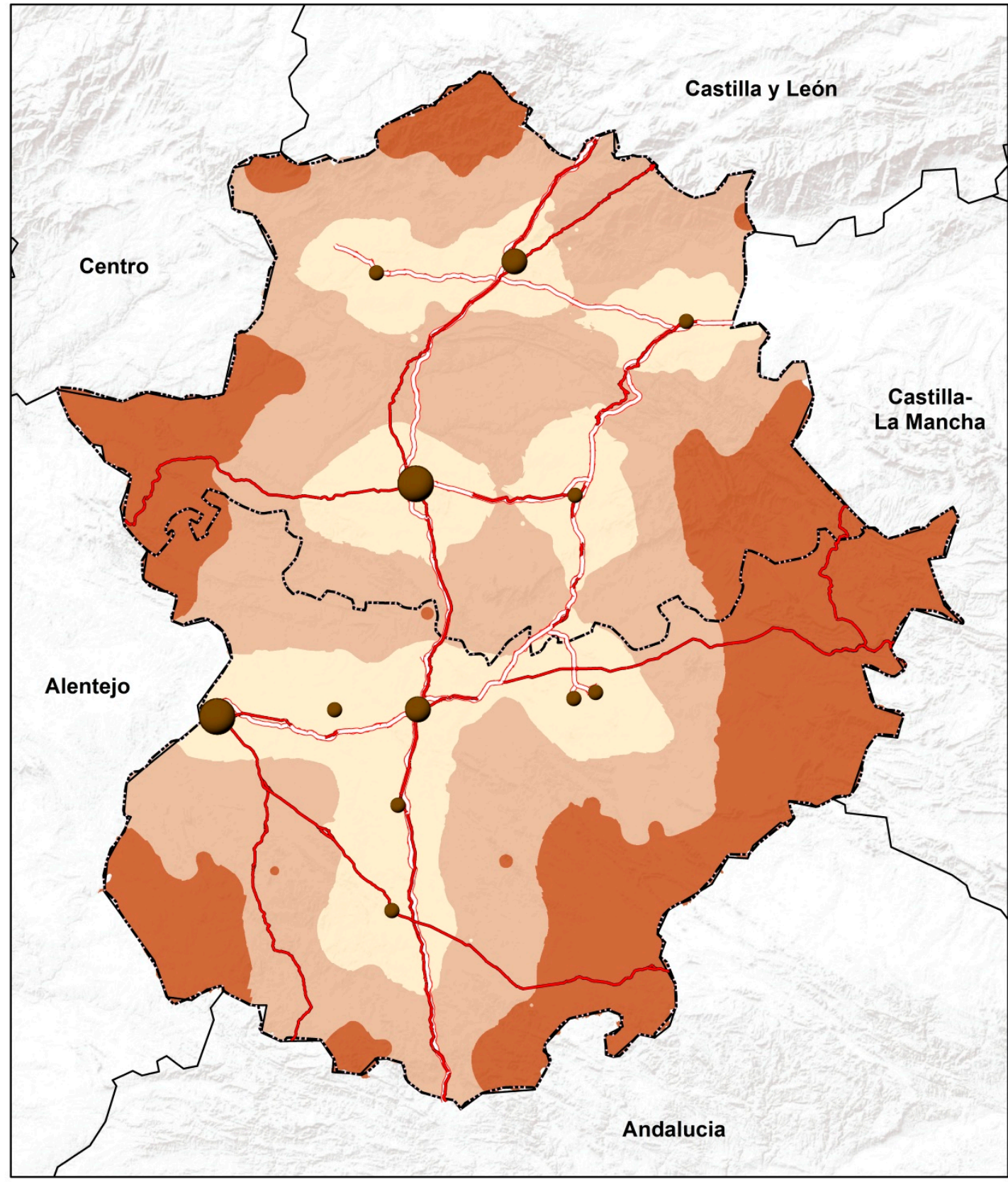

\section{Small Cities \\ Population 2019}

- $10,000-40,000$ Inhabitants

$40,000-60,000$ Inhabitants

$60,000-150,000$ Inhabitants
Accessibility from rural to urban areas Minutes

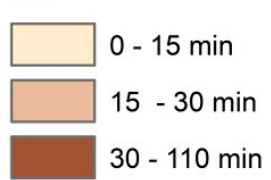

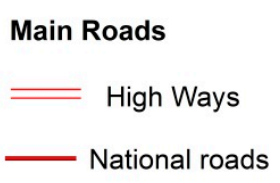

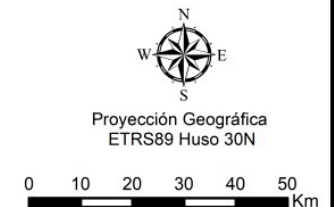

Figure 3. Accessibility to urban network of Extremadura. Source: the authors.

The population of the 12 cities with the highest urban rank does not reach $50 \%$, so it can be deduced that the other half lives in nuclei with less than 10,000 inhabitants, being then Extremadura the Spanish region with the largest rural population in the country. Later, although it has been mentioned 
that these are small rural cities and there are no large urban concentrations, it must be considered that $66 \%$ of the Extremadura population lives less than 15 min of travel to one of these 12 small cities and $87 \%$ less than $30 \mathrm{~min}$. Therefore, there is a less population that is distributed over a very peripheral fringe that is very isolated and inaccessible. In addition, other adverse factors for their development, almost exclusively agrarian, should be analyzed in these areas, such as the mountainous reliefs of the north, east and south of the region, in addition to the rigid and limiting border with Portugal to the west. These are the most depressed areas of Extremadura and with persistent emigration and regressive demographic dynamics, so they do not exceed 10 inhabitants $/ \mathrm{km}^{2}$.

Regarding the evolution of the population (Table 1), it is verified that the small cities have experienced a growth of $84.5 \%$ from 1950 to the present. The rural areas have registered losses directly proportional to the distance, in such a way that the municipalities located in the perimeter of the 15-min journey to the small cities show a decrease of close to $28 \%$. While, in the range up to $30 \mathrm{~min}$, the losses already exceed $50 \%$ of its population (double that in the municipalities closest to the small cities).

Finally, in the most remote municipalities (with travel times greater than $30 \mathrm{~min}$ ), the losses exceed $60 \%$. Therefore, the existing correlation between urban accessibility and population evolution is evident, or, in other words, the influence of small cities in stabilizing the population or slowing down the processes of rural depopulation.

Table 1. Evolution of the population $(1950=100)$.

\begin{tabular}{ccccc}
\hline & Small Cities & $\mathbf{< 1 5}^{\prime}$ & $\mathbf{1 5}^{-3 \mathbf{0}^{\prime}}$ & $\mathbf{> 3 0}^{\prime}$ \\
\hline 1950 & 100.0 & 100.0 & 100.0 & 100.0 \\
1960 & 116.2 & 102.9 & 97.0 & 93.1 \\
1970 & 125.4 & 83.8 & 71.3 & 69.2 \\
1975 & 127.6 & 77.5 & 64.8 & 59.9 \\
1981 & 141.1 & 72.3 & 59.3 & 54.2 \\
1986 & 155.2 & 74.5 & 58.5 & 53.6 \\
1991 & 159.0 & 72.0 & 54.4 & 48.4 \\
1996 & 157.8 & 75.9 & 55.9 & 48.7 \\
2001 & 163.7 & 75.6 & 54.1 & 46.5 \\
2006 & 174.7 & 75.6 & 52.4 & 44.2 \\
2011 & 184.9 & 76.6 & 51.8 & 42.9 \\
2016 & 186.7 & 75.2 & 49.9 & 40.9 \\
2019 & 184.5 & 72.3 & 47.4 & 38.7 \\
\hline ource: the authors based on the National Statistics Institute (2020).
\end{tabular}

Without a doubt, the size of the municipalities is also another factor of depopulation, due to the limitations of the smaller towns, since they do not have the most essential facilities and services or even more employment than that generated in the agricultural sector with permanent and declining labor surpluses, especially in smallholder areas. However, in Extremadura, even municipalities with less than a thousand inhabitants have remained stabilized between 1990 and 2010, although it has had a slight regressive trend due to the effect of quite negative natural growth.

In this case, the distance variable is more defining than the one referring to the size of the population centers, since the small municipalities of irrigated land and those closest to the small cities, which have an acceptable dynamism, contrast those found in the peripheral and mountainous areas and that are at serious risk of depopulation. As Copus [8] indicates, a "complex mix of socioeconomic processes, some sensitive to spatial proximity, others 'liberated' by transport and IT improvements, now driven by 'organized proximity" is developing.

As seen in Figure 4 and Table 2, the degradation of the values with distance remains constant throughout the period studied. This is proof that the city system, already consolidated in the middle of the last century, was already exerting its influence, although much more limited to the closest and most accessible municipalities. 


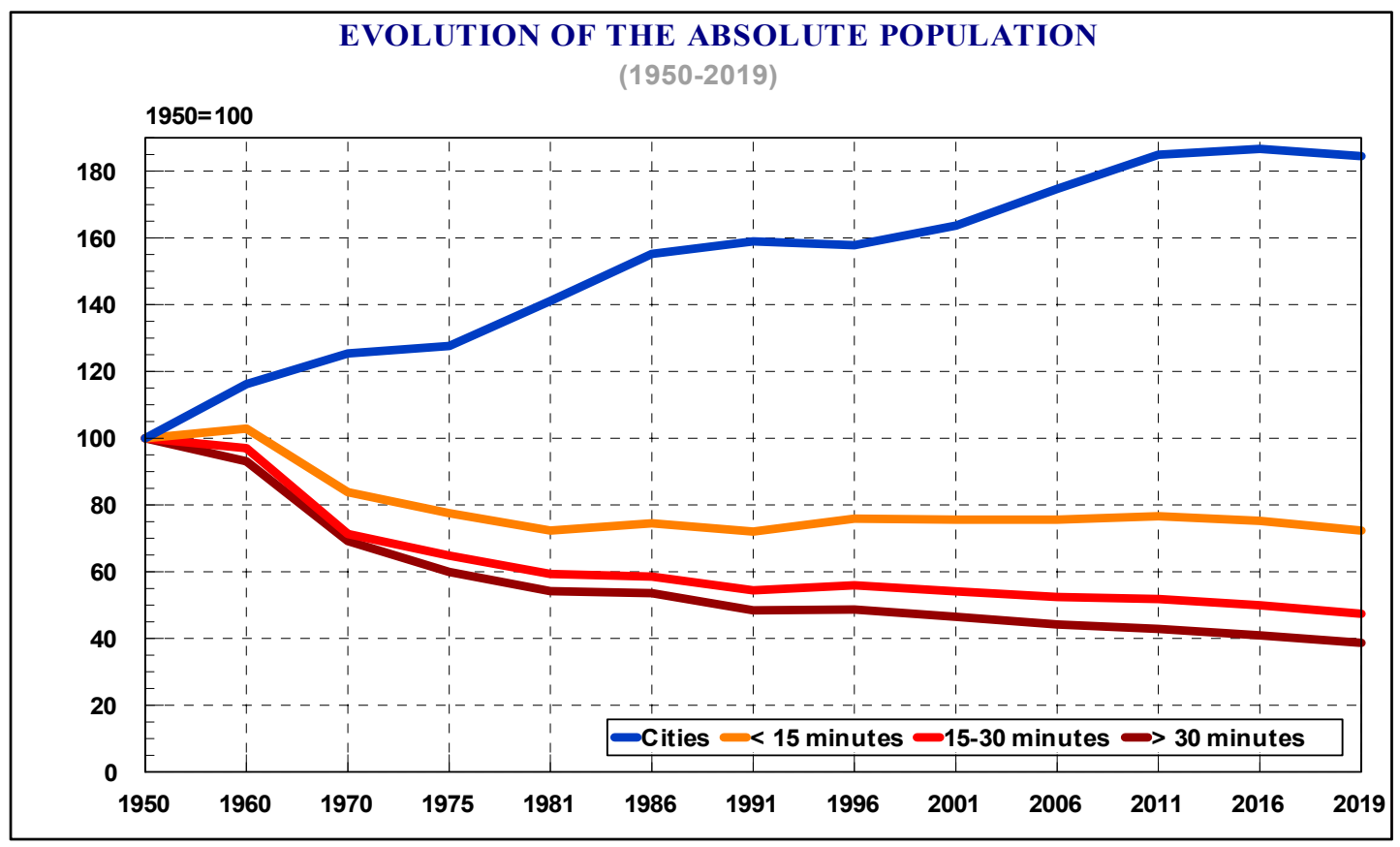

Figure 4. Evolution of the absolute population. Source: the authors, based on National Statistics Institute (2020).

First, the intense losses in all rural areas between 1960 and 1981 can be seen, a period in which the municipalities of the two most peripheral fringes lost more than $40 \%$ of their population due to the rural exodus. These losses began to diminish in 1981 in all rural areas, but largely after 1991, especially in areas closer to small cities. However, the stability described is considered "regressive" due to the effects of increasingly negative natural growth and not so much due to emigration, as will be seen below.

The rural municipalities with greater accessibility to the cities separated from the rest very early, in 1960, since their proximity allowed their population to move to the cities through public transport. The towns on the other two most distant fringes presented a superimposed trend until 1970, from which time the road network, public transport and the availability of own vehicles were improved. In short, the accessibility to the small cities was improved and the population of the municipalities a little further away (with movements between 15 and $30 \mathrm{~min}$ ) began to move to the cities, distancing themselves from the more distant towns and stabilizing their population. There are no great differences between the municipalities of the two most peripheral fringes, but there is a decoupling that was increasing imperceptibly, but constantly.

It is necessary to take into account the strong degradation of values after $15 \mathrm{~min}$ of travel, since cities are small with a limited urban range and have a limited influence beyond the distance from which a significant gap between some municipalities and others is appreciated. In addition, it is necessary to point out the intense differences between the demographic behavior in the small cities and that already observed in the rural municipalities closest to them. This is a consequence not so much of current factors, but of emigration from the fifties to the eighties of the century past, whose negative effects reach to the present and are still projected into the future.

Regarding the distribution of the regional population of the four ranges of municipalities (the small cities and their three areas of influence) (Table 2), it should be noted that, in 1950, only $20 \%$ of the population lived in the small cities, which would reach up to $40 \%$ considering the municipalities within 15 min compared to $26 \%$ of the population that was distributed in the most peripheral areas. 
Table 2. Proportion of the population according to the accessibility of the municipalities.

\begin{tabular}{lccccc}
\hline & Small Cities & $<\mathbf{1 5}$ min & $\mathbf{1 5}-\mathbf{3 0} \mathbf{~ m i n}$ & $>\mathbf{3 0} \mathbf{~ m i n}$ & Total Population \\
\hline $\mathbf{1 9 5 0}$ & 20.4 & 18.9 & 34.7 & 25.9 & 100 \\
$\mathbf{1 9 6 0}$ & 23.5 & 19.3 & 33.3 & 23.9 & 1000 \\
$\mathbf{1 9 7 0}$ & 30.5 & 18.8 & 29.4 & 21.3 & 100 \\
$\mathbf{1 9 7 5}$ & 33.1 & 18.6 & 28.5 & 19.7 & 100 \\
$\mathbf{1 9 8 1}$ & 37.4 & 17.7 & 26.7 & 18.2 & 100 \\
$\mathbf{1 9 8 6}$ & 39.6 & 17.6 & 25.4 & 17.4 & 100 \\
$\mathbf{1 9 9 1}$ & 41.9 & 17.6 & 24.4 & 16.2 & 100 \\
$\mathbf{1 9 9 6}$ & 41.0 & 18.3 & 24.7 & 16.1 & 100 \\
$\mathbf{2 0 0 1}$ & 42.6 & 18.2 & 23.9 & 15.3 & 100 \\
$\mathbf{2 0 0 6}$ & 44.8 & 18.0 & 22.8 & 14.4 & 100 \\
$\mathbf{2 0 1 1}$ & 46.4 & 17.8 & 22.1 & 13.7 & 100 \\
$\mathbf{2 0 1 6}$ & 47.5 & 17.7 & 21.6 & 13.2 & 100 \\
$\mathbf{2 0 1 9}$ & 48.4 & 17.6 & 21.1 & 12.9 & 100 \\
\hline
\end{tabular}

Currently, almost $50 \%$ of the population lives in the small cities and only $13 \%$ live in the most inaccessible areas, whose proportion of the population has been cut in half. For their part, the municipalities within 15 min have kept their population very stable, with a loss of only one percentage point, despite the emigration they have suffered. Something similar occurs with the towns located on the border from 15 to $30 \mathrm{~min}$, which register moderate losses, although they already reach seven percentage points.

Thus, the evolution of the absolute population is nothing more than a synthesis of the vital events that demographic dynamics gathers, so that the variables of Gross Birth Rate, Gross Mortality Rate, Vegetative Growth Rate and Migratory Balance Rate also maintain a degradation proportional to distance and accessibility, as can be seen in the following table. As Oliveira states [58], "there is positive growth spillovers from urban to rural regions in terms of population. These effects are decreasing with distance".

The degradation based on accessibility is especially evident in the natural growth variable, as reflected in Table 3 and Figure 5. Natural growth is a synthesis variable in which only the small cities still have a slightly positive balance close to zero increase. Thus, the differences between the rest of the municipalities are very sharp and constant and with a very negative trend throughout the entire period. Currently, the values range from -3.9 per thousand (municipalities closest to the small cities) to -9.5 per thousand (for the most remote municipalities).

Table 3. Urban accessibility and demographic dynamics.

\begin{tabular}{|c|c|c|c|c|c|c|c|c|}
\hline & \multicolumn{4}{|c|}{ Gross Birth Rate } & \multicolumn{4}{|c|}{ Gross Mortality Rate } \\
\hline & Small Cities & $<15 \min$ & $15-30 \mathrm{~min}$ & $<30 \min$ & Small Cities & $<15$ min & $15-30 \mathrm{~min}$ & $<30 \min$ \\
\hline 1986-1990 & 13.5 & 13.2 & 12 & 11 & 7.3 & 9.8 & 11.2 & 12.3 \\
\hline 1991-1995 & 12.2 & 11.6 & 10 & 9.1 & 7.5 & 9.7 & 11.3 & 13 \\
\hline 1996-2000 & 10.8 & 9.7 & 8.5 & 7.8 & 8 & 10 & 11.2 & 12.6 \\
\hline 2001-2005 & 10.9 & 8.9 & 7.7 & 6.9 & 8.1 & 10.1 & 11.4 & 13 \\
\hline 2006-2010 & 11.6 & 8.6 & 7.2 & 6.6 & 7.6 & 10.2 & 11.3 & 13.4 \\
\hline 2011-2015 & 10.1 & 7.9 & 6.7 & 6 & 7.8 & 10.5 & 12.2 & 13.9 \\
\hline \multirow[t]{3}{*}{ 2016-2019 } & 8.9 & 7.5 & 6.3 & 6 & 7.9 & 11.4 & 13 & 15.1 \\
\hline & \multicolumn{4}{|c|}{ Vegetative Growth Rate } & \multicolumn{4}{|c|}{ Migratory Balance Rate } \\
\hline & Small Cities & $<15 \min$ & $15-30 \mathrm{~min}$ & $<30 \mathrm{~min}$ & Small Cities & $<15 \mathrm{~min}$ & $15-30 \mathrm{~min}$ & $<30 \mathrm{~min}$ \\
\hline 1986-1990 & 6.2 & 3.3 & 0.9 & -1.3 & -1.3 & -10.2 & -15.3 & -19 \\
\hline 1991-1995 & 4.7 & 1.8 & -1.3 & -3.9 & -6.2 & 8.6 & 6.7 & 5.2 \\
\hline 1996-2000 & 2.8 & -0.3 & -2.7 & -4.8 & 4.6 & -0.3 & -4.1 & -4.6 \\
\hline 2001-2005 & 2.8 & -1.2 & -3.7 & -6.1 & 10.2 & 0.3 & -2 & -4 \\
\hline 2006-2010 & 4 & -1.6 & -4.1 & -6.8 & 7.4 & 4.1 & 1.8 & 0.7 \\
\hline 2011-2015 & 2.3 & -2.6 & -5.4 & -8 & -0.3 & -1.1 & -1.8 & -1.6 \\
\hline 2016-2019 & 1 & -3.9 & -6.7 & -9.1 & -4.9 & -7 & -7.2 & -9.5 \\
\hline
\end{tabular}


The most distant municipalities started the 1980s with negative values. Then, in the early 1990s, towns with 15 to $30 \mathrm{~min}$ of travel had negative natural growth. Later, towards the end of the century, the municipalities closest to the small cities were the ones that reached the negative balances. Thus, there was a slight slowdown in the decreasing trend around the 2006-2010 period due to slight immigration, which was much more noticeable in the case of the small cities. In the last two five-year periods, the drop has been very intense, even in the small cities, since they have also registered negative migratory balances, as will be seen below.

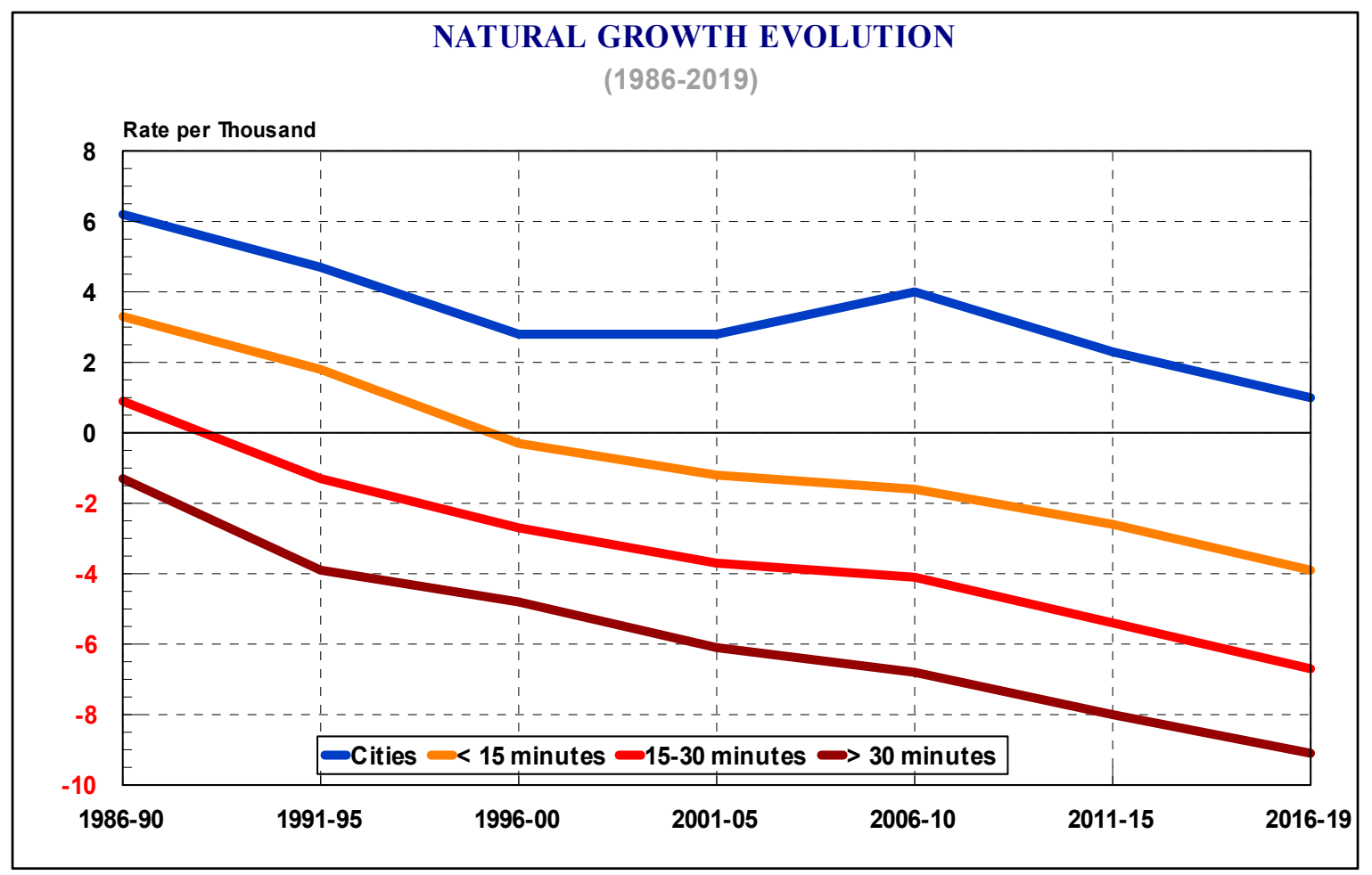

Figure 5. Evolution of the natural growth rate. Source: the authors, based on National Statistics Institute (2020).

The variable of migration balances (Figure 6) is more complex in all cases, due to its more unstable and changing nature, although a series of behavior guidelines can be specified.

Throughout the series, five-year periods with a predominance of emigration and others of immigration alternate, but most of the time, maintaining degradation in one sense or another depending on the accessibility to the small cities. In any case, it should be borne in mind that this variable owes its complexity to a greater dependence on external and, above all, economic factors.

The series begins in the second half of the eighties with negative values in all cases. This period coincides with the entry of Spain into the EU on 1 January 1986. At this time, significant resources from the ERDF Funds entered into infrastructure and were accompanied by Spanish government policies in construction and housing to deal with the Unemployment pockets that the late industrial reconversion was generating after the unstable period of transition from dictatorship to democracy. Simultaneously, works were undertaken for the Universal Expo in Seville and for the Olympics in Barcelona (1992), so in that five-year period, a significant offer of construction employment emerged, causing massive emigration from rural areas, but even from cities as well.

The following five-year period (1991-1995) was characterized by a generalized economic recession and by the stoppage of activity in the construction sector. For this reason, a large part of the previous emigrants returned to their rural hometowns, so that in this period, important immigration movements predominated, although not to the same extent as in the previous period. In the small cities, emigration 
remained and with more intensity because of the lack of housing and the departure of a certain young population towards the closest towns.

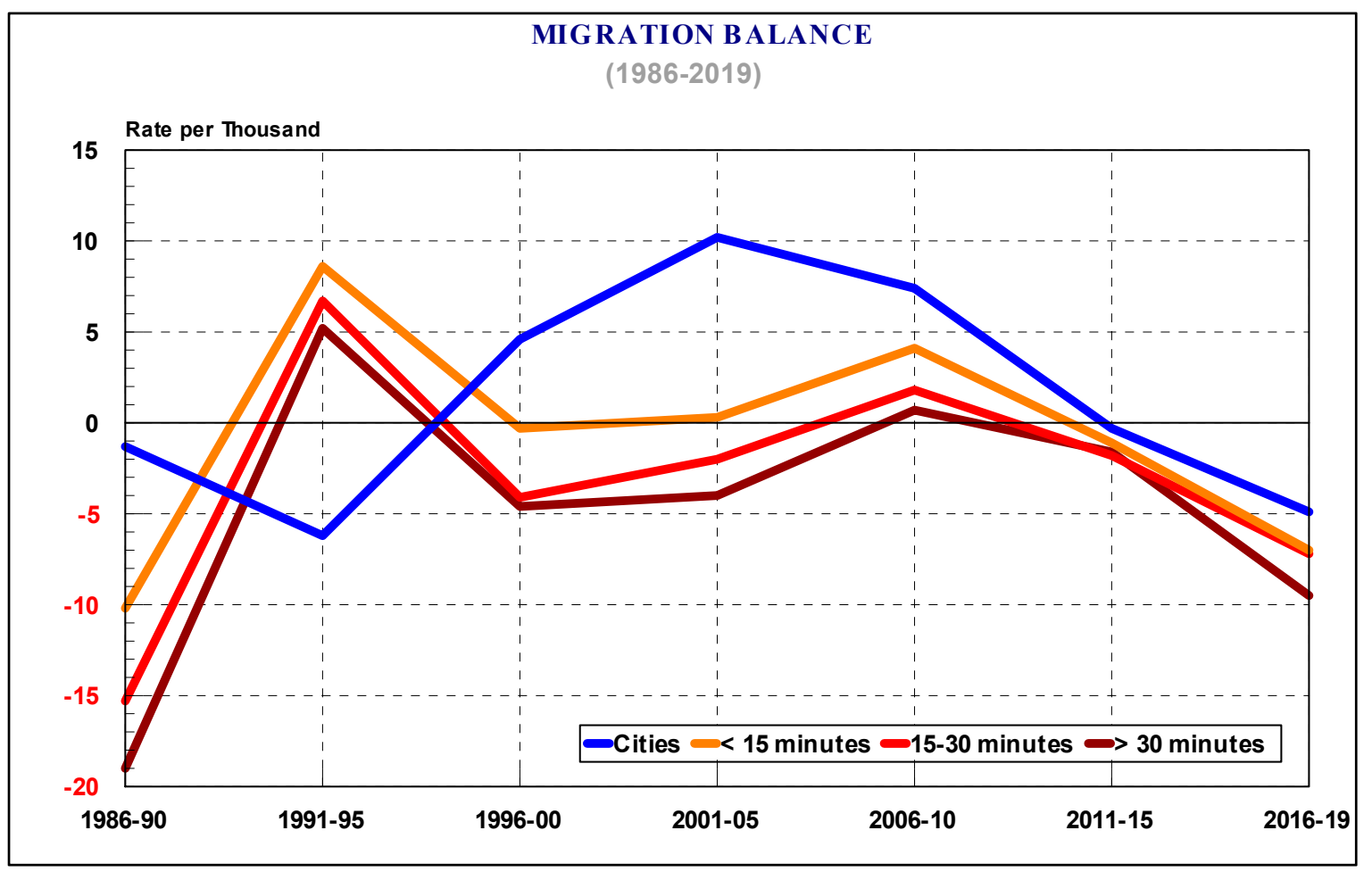

Figure 6. Evolution of the migration balance rate. Source: the authors, based on National Statistics Institute (2020).

1996-2010 was a long period of economic development and a strong attraction for foreign immigration, which was concentrated in the cities and which finally reached all rural areas, to a greater or lesser extent, in the five-year period 2006-2010.

In the current decade, there has been a general emigration to all population centers due to the consequences of the economic crisis that has caused the return of a large part of foreign immigrants to their countries of origin. If there have been slightly negative data in the first half of the decade, in the second they have reached important values. Job losses in cities have also been important for their respective areas of influence. For this reason, emigration has intensified until reaching the second maximum of the entire period. Throughout the series, the degradation of the values according to distance and accessibility has maintained, with the only exception of the small cities during the five-year period 1991-1995.

The small cities have been able to limit the losses due to emigration only in the closest towns. However, they have not been able to mitigate the losses due to negative natural growth, since it is due to long-range structural factors, such as aging and high mortality, on one hand, and the drop in fertility and birth rate, on the other. The effects of emigration are very noticeable also in other five variables, with which the population structure could be synthesized: the average age, the active population, the young population, the senile population and, above all, thedependency index (Table 4). 
Table 4. Relationship between urban accessibility and demographic dynamics.

\begin{tabular}{ccccc}
\hline Minutes/Rates & Small Cities & $\mathbf{< 1 5}^{\prime}$ & $\mathbf{1 5}^{-3 \mathbf{3 0}^{\prime}}$ & $\mathbf{> 3 0}^{\mathbf{\prime}}$ \\
\hline Total number of municipalities & 12.0 & 93.0 & 176.0 & 101.0 \\
Population 2019 (\%) & 48.8 & 17.6 & 21.1 & 12.9 \\
Average age & 41.1 & 46.3 & 49.1 & 50.2 \\
Active population (\%) & 67.8 & 63.7 & 61.0 & 60.3 \\
Young population (\%) & 15.5 & 11.1 & 9.6 & 9.5 \\
Senile population (\%) & 16.7 & 25.2 & 29.5 & 31.1 \\
Dependency Index (\%) & 49.8 & 60.5 & 67.7 & 71.1 \\
\hline Source the authors based on the National Statistics Intitute (2020) &
\end{tabular}

The average age of the population ranges from 41 years in the small cities to 50 years in municipalities located more than $30 \mathrm{~min}$ away. This is due to the continuous decrease in birth rates and the youth population group, which is $15.5 \%$ in the small cities, while in towns that are more distant it is already below $10 \%$. This is mainly a consequence of low fertility rates and the lack of women of childbearing age due to the persistent effects of emigration. The senile population, on the other hand, is higher than the young population group in all cases, even in the small cities, where it reaches almost $17 \%$. This senile population almost doubles in the most remote municipalities. Consequently, the labor force is progressively decreasing from $70 \%$ to $60 \%$.

The dependency index, which ranges between values of $50 \%$ and more than $70 \%$, indicates that there are more than 70 passive people for every 100 active people in the most remote towns because of the extremely high aging that they suffer. It is evident, therefore, that the demographic dynamics are very regressive, with little capacity for regeneration, especially in the smaller municipalities and far from the small cities.

\section{Discussion and Conclusions}

According to the data presented, the influence of the small cities on the development of their functional areas (almost exclusively rural) to which they offer facilities and services and, above all, diversification of activities, employment and income, is very evident, favoring the stability of the rural population. Extremadura, with a polycentric system of well-distributed small and medium cities in most of the regional territory, has managed to maintain half of its population in rural areas, with the highest percentage of all the autonomous communities in Spain. In addition, a certain stability of the rural population has been fostered in the region, although this is a "regressive" stability with a slightly negative trend since 1980. This is mainly due to a negative natural growth that is already beginning to affect even cities due to the progressive and intense aging and the drastic drop in fertility and birth rates. These characteristics are very widespread (higher in rural areas) due to the effects of emigration from 1950 to 1980, which dragged between $40 \%$ and $60 \%$ of the population from rural areas.

It is also very clear that urban influence in rural areas is degrading with distance, consequently with urban accessibility, which depends on the range and size of each city, as well as on infrastructure and the transport system.

The polycentric urban system in Extremadura is made up of a group of twelve small cities whose influence in their rural areas does not exceed, sometimes, the first border of the 15-min journey and gradually degrades until it loses almost all influence beyond $30 \mathrm{~min}$. It should be borne in mind that these are small cities with little labor supply except for the cities that form the basic structure and with a greater urban range, in which case their influence does extend even beyond $30 \mathrm{~min}$. In any case, within the maximum radius of $30 \mathrm{~min}$ of travel $87 \%$ of the total regional population settles. Cities have undoubtedly slowed down the process of rural depopulation, but they have not been able to stop the structural effects of emigration in previous decades or the drop in fertility rates. Furthermore, there is no doubt that Extremadura, a border inland region with the highest percentage of rural population in Spain, maintains a demographic dynamism superior to other regions with the same characteristics, especially with respect to the northern half regions of the Spanish country that have 
numerous abandoned rural centers and a very regressive demographic dynamism. These are the so-called "empty Spain" and are very depopulated. This depopulation is the result of a settlement of widely scattered small municipalities and without cities or county seats capable of retaining the population in rural areas. In fact, as Reig et al. state [56], “ $58 \%$ of rural municipalities can be classified as accessible, since the travel time of their inhabitants to access the services offered by cities is less than $45 \mathrm{~min} .70 \%$ of the population of rural municipalities live in them". It could be considered that it is a large volume of population, but it is not comparable to that registered in Extremadura and less than $30 \mathrm{~min}(87 \%)$.

In any case, there are extensive peripheral areas in Extremadura that are very distant from the small cities and very inaccessible. These have a very regressive socioeconomic (basically agrarian) and demographic development, in such a way that most of their municipalities do not even reach 10 inhabitants per $\mathrm{km}^{2}$. Thus, as EU indicates in The Territorial Agenda 2020 [6], "in rural areas small and medium-sized towns play a crucial role; therefore it is important to improve the accessibility of urban centers from related rural territories to ensure the necessary availability of job opportunities and services of general interest".

The proposal made in this article involves integrating rural areas into regional dynamics, for which it would be necessary to decentralize development through territorial planning. This, without a doubt, must be based on the impulse of the traditional county seats, which have gradually lost their traditional functionality in the context of economic backwardness and emigration. In the 1990s, the regional government of Extremadura carried out the second administrative decentralization towards the main cities, but some small cities and county seats (mainly on the periphery) were relegated, so a third decentralization would must be carried out towards these towns, as well as its corresponding functional areas.

According to CES [41], for peripheral rural municipalities, geographic characteristics and territorial planning are key, since the low accessibility or the absence of more populated nearby municipalities are the phenomena that hinder their integration into a dynamic of rural development.

In Figure 7, it can be seen how in the easternmost strip (the most extensive and continuous) three small cities (traditionally county seats) have been incorporated, however, they currently have lost most of their previous functionality. From north to south, they are Herrera del Duque (in the county of La Siberia), Castuera (in La Serena) and Azuaga, in La Campiña. 


\section{Urban Network Proposal}
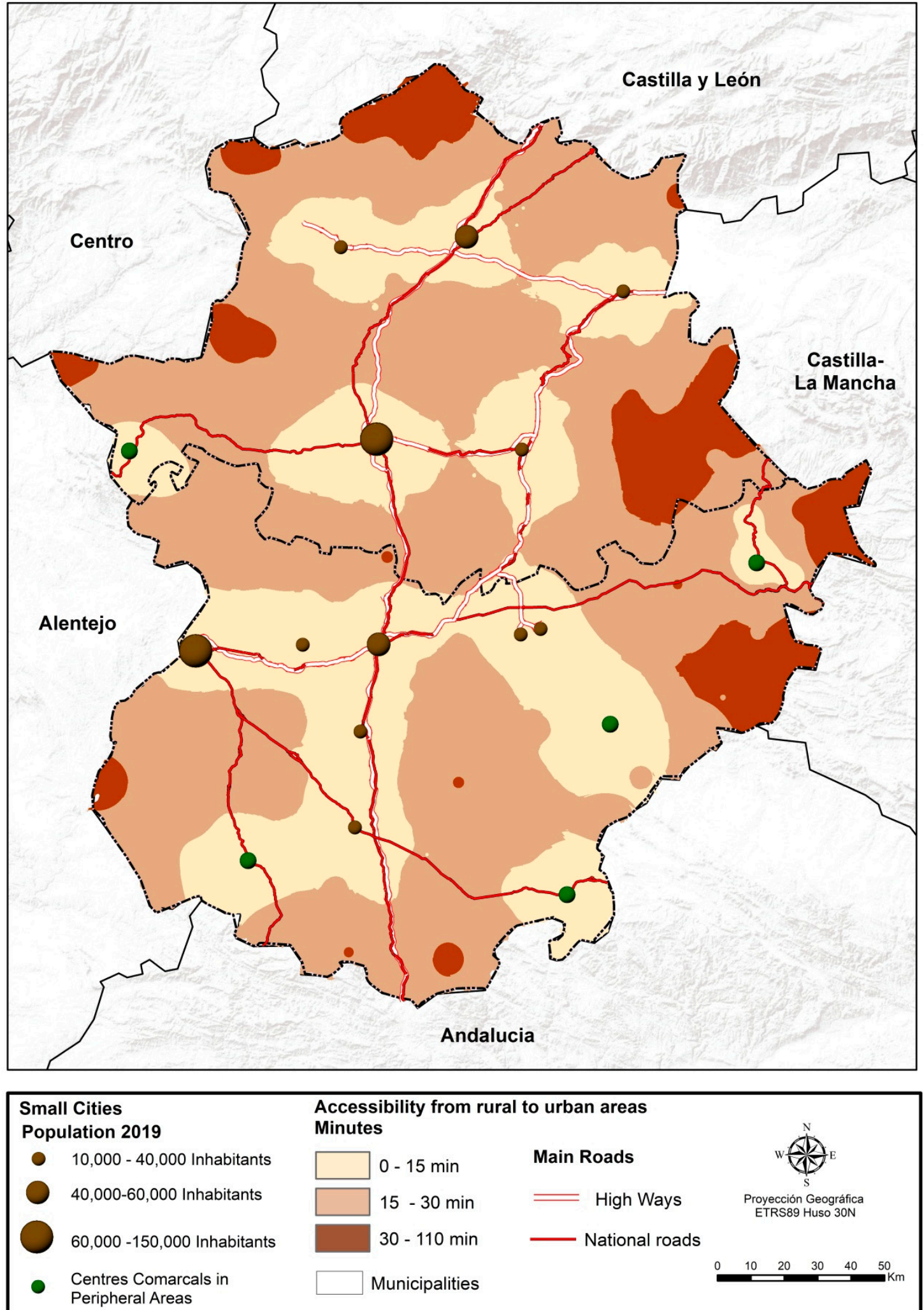

Figure 7. Urban network proposal of Extremadura. Source: the authors.

In the other western fringe, bordering Portugal, two other small cities have been included with a range that could be considered third order. These are Valencia de Alcántara in the central zone and Jerez de los Caballeros in the south, being more distant from the border, but with the possibility 
of extending its influence to it. These two municipalities are also traditional county seats that have managed to maintain two commercial subareas, especially Valencia de Alcántara because it is located more than an hour from the nearest city (Cáceres).

Of the five cities mentioned, four already have railway routes, although very obsolete and with little capacity (Jerez de los Caballeros, Valencia de Alcántara, Castuera and Llerena, near Azuaga), that should be improved. Furthermore, some highways are also pending to be built: Zafra-Jerez de los Caballeros-Huelva, Badajoz-Zafra-Llerena-Azuaga-Córdoba and Badajoz-Valencia, perhaps by Castuera or Herrera del Duque. These main roads would make these areas permeable, provide them with greater accessibility and incorporate them into national and international circuits, promoting investment and decentralization of development. If these five cities, located in the most peripheral areas, were promoted, the population that could be less than $30 \mathrm{~min}$ from any of those 17 cities that appear on the previous map would rise to $98 \%$ of the regional total. Only $2 \%$ of the population would be outside this 30-min perimeter.

There would be four small areas, almost enclaves that do not have county seats, so it would be necessary to articulate specific development projects to achieve the stability of a minimum population in these more backward, aged and isolated areas. In this case, there are small mountain regions, Sierra de Gata and Las Hurdes in the Central System, Villuercas and southern Siberia in Montes de Toledo, as well as Alcántara in the northern border area and in the Riberos del Tajo, also with steep slopes by the nesting of the river system. Some of these four regions, due to their centuries-old socioeconomic backwardness, have already been the subject of different specific development plans throughout the 20th century, especially in the second half, but have not been able to restraint their inertia.

These more peripheral areas, which are socioeconomically backward and have a very regressive demographic dynamic, show that urban accessibility and the integration of rurban partnerships are essential for the stability of the rural population and its demographic dynamism. All the specific socioeconomic plans for these areas have previously failed. Not even the EU's own rural development programs have the same opportunities, nor are their achievements as noticeable in these peripheral areas of Extremadura or in the northern half of Spain

Any strategy to meet the demographic challenge must consider a territorial planning that will ultimately allow the decentralization of development and the overcoming of existing imbalances. Small centers of population and those more distant from cities only have the capacity to generate employment in an agricultural sector in decline and with permanent labor surpluses and cannot provide acceptable facilities and services. Only a polycentric system of cities can contribute to the generation of employment and income outside the agricultural sector, as well as to the provision of quality services, not only for their inhabitants, but also for those in their rural environments.

Now that the new rural development programs for the next EU programming period (2021-27) are beginning to be planned, these options—not yet taken into account-of rurban partnerships and integrated territorial investments, which can guarantee the success of European investments in the face of the demographic challenge and rural depopulation, as is evident in this region and without any funding, should be considered.

As a final conclusion, the results confirm the initial hypotheses, in the sense that "the future of rural areas is increasingly dependent on the development of cities. Balanced urban systems-and in their case polycentric ones-are of greater interest in Europe because of their better capacity to organize innovative systems in the development, dissemination and support of local economies. Cooperation between the city and its environment is key to restructuring the territory and generating responsible change [ ... ]", according to Ortega [59]. Moreover, the other hand, these results have demonstrated the functioning of the rurban partnerships and their functionality in the face of the demographic challenge, which can be easily extrapolated to other environments. 
Author Contributions: Conceptualization, J.L.G.G. and A.N.M.; Formal analysis, J.L.G.G. and A.N.M.; Investigation, J.L.G.G. and A.N.M.; Methodology, J.L.G.G. and A.N.M.; Software, A.N.M.; Validation, J.L.G.G. and A.N.M.; Writing—original draft, J.L.G.G. and A.N.M.; Writing—review \& editing, J.L.G.G. and A.N.M. All authors have read and agreed to the published version of the manuscript.

Funding: ERDF (European regional development fund), European Social Fund (ESF) and Government of Extremadura (Spain) funded this research and the APC to the DESOSTE research group (Grant number GR18052).

Conflicts of Interest: The authors declare no conflicts of interest.

\section{References}

1. Comunicación de la Comisión al Consejo y al Parlamento Europeo: 'Europa 2000': Perspectivas del Desarrollo del Territorio de la Comunidad Comisión de las Comunidades Europeas; Comisión Europea: Brussels, Belgium, 1990.

2. Agenda Urbana Española 2019; Ministerio de Fomento: Madrid, Spain, 2019.

3. Hernández Luque, J.M. La Reforma de la Política Agraria Común para el período 2021-2027. Rev. Desarro. Rural (CEIPREX y ADERCO) 2019, XXIV, NO. 43.

4. Ponencia de estudio para la adopción de medidas en relación con la despoblación rural en España, constituida en el seno de la Comisión de Entidades Locales. In Boletín Oficial de las Cortes Generales (BOCG); Senado: Spain, 2015.

5. Comisionado Nacional para el Reto Demográfico. La Estrategia Nacional frente al Reto Demográfico; Ministerio de Política Territorial y Función Pública: Madrid, Spain, 2019.

6. Agenda Territorial de la Unión Europea 2020: Hacia una Europa Integradora, Inteligente y Sostenible de Regiones Diversas; Reunión ministerial informal de los ministros responsables de ordenación del territorio y desarrollo territorial; European Union: Gódollo, Hungary, 2011.

7. Comisión Europea. Estrategia Territorial Europea. Hacia un Desarrollo Equilibrado; Oficina de Publicaciones Oficiales de las Comunidades Europeas: Luxembourg, 1999.

8. Copus, A. New Relationships between Rural and Urban Areas in EU Countries; OECD: Paris, France, 2015. [CrossRef]

9. Grupo de Trabajo sobre Estrategias Integradas en Actuaciones de Desarrollo Urbano Sostenible(RIU). In Orientaciones Para la Definición de Estrategias de Desarrollo Urbano Sostenible Integrado en el Período 2014-2020; Ministerio de Fomento: Madrid, Spain, 2015.

10. Artmann, J.; Huttenloher, C.; Kawka, R.; Scholze, J. Partnership for Sustainable Rural-Urban Development: Existing Evidences; Publications Office of the EU: Brussels, Belgium, 2013.

11. OCDE. Placed-Based Policies for Rural Development; Extremadura. Spain (case study); OECD Head Quarters: Paris, France, 2004.

12. Regidor, J.G. Junta de Extremadura. In Desarrollo Rural de Base Territorial: Extremadura (España); Consejería de Desarrollo Rural; Ministerio de Agricultura, Pesca y Alimentación (MAPA): Madrid, Spain, 2006; p. 283.

13. The ESPON 2006 Programme, Programme on the Spatial Development of an Enlarging European Union; European Union: Luxembourg, 2003.

14. La mejora de la aplicación de la Agenda Territorial de la Unión Europea 2020; Diario Oficial de la Unión Europea (2015/C 195/05): Brussels, Belgium, 2015.

15. Opinion of the European Committee of the Regions. In The Improvement of the Implementation of the Territorial Agenda of the European Union 2020; European Union: Brussels, Belgium, 2015.

16. Ahner, D. Urban-Rural Seminar; European Union: Brussels, Belgium, 2009.

17. The ESPON 2013 Programme EDORA (European Opportunities for Rural Areas); European Union: Luxembourg, 2011.

18. Robust:Rural-Urban Europe: European Research Project; European Union. Available online: https://rural-urban. eu/ (accessed on 15 April 2020).

19. Rural-Urban Partnerships. An Integrated Approach to Economic Development, OECD Rural Policy Reviews; OECD: Paris, France, 2003.

20. Comité Europeo de las Regiones. Las Inversiones Territoriales Integradas (ITI): Un Desafío para la Politica de Cohesión de la UE Después de 2020; Diario Oficial de la Unión Europea (2018/C 176/10): Brussels, Belgium, 2018.

21. Acta Única Europea.; Comunidad Económica Europea: Luxemburgo; La Haya, The Netherlands, 1986. 
22. The Future of the Rural World. In Communication from the Commission to the European Parliament and the Council-COM(88); European Commission: Luxembourg, 1988.

23. The Community Initiative for Rural Development: LEADER, Information Memo, 25 July 1990; European Commission: Brussels, Belgium, 1990.

24. Programa Nacional Proder I.; Ministerio de Agricultura Pesca y Alimentación: Madrid, Spain, 1996.

25. Agenda 2000 for a Stronger and Wider Union; Commuication of European Union: Brussels, Belgium, 1997.

26. Consejo de Corfú. In Conclusiones de la Presidencia; Consejo de Europa: Brussels, Belgium, 1994.

27. Europa 2000 +. Cooperación para la Ordenación del Territorio Europeo; Comisión Europea: Luxembourg, 1995.

28. Especial Conferencia de Cork "Un Medio Rural Vivo. Leader Magazine, 1996; 13.

29. $\quad 2^{a}$ Conferencia Europea Sobre Desarrollo Rural: Plantar las Semillas del Mundo Rural del Mañana Las Perspectivas de la Politica Rural en una Europa Ampliada; Comisión Europea: Brussels, Belgium, 2003.

30. Hildebrand, A. Política de Ordenación del Territorio; Universidad de Sevilla: Sevilla, Spain, 1996.

31. Dictamen del Comité de las Regiones sobre la. In Perspectiva Europea de Ordenación del Territorio Diario Oficial; Comité de las Regiones Europeas: Brussels, Belgium, 1999; n C 093 de 06/04/1999.

32. Dictamen del Comité Económico y Social Europeo sobre la «Propuesta de Reglamento del Consejo por el que se Establecen Disposiciones Generales Sobre el Fondo Europeo de Desarrollo Regional, el Fondo Social Europeo y el Fondo de Cohesión; Diario Oficial de la Unión Europea: Brussels, Belgium, 2005; (COM(2004) 492 final-2004/0163 (AVC).

33. Tercer Informe Sobre la Cohesión Económica y Social:Una Nueva Asociación para la Cohesión, Convergencia, Competitividad, Cooperación; Oficina de Publicaciones Oficiales de las Comunidades Europeas: Luxembourg, 2004.

34. Carta de Leipzig. Territorial Agenda of the European Union, Towards a More Competitive and Sustainable Europe of Diverse Regions; Comisión Europea: Leipzig, Germany, 2007.

35. El Libro Verde Sobre la Cohesión Territorial: El Camino a Seguir; Oficina de publicaciones oficiales de las Comunidades Europeas: Luxembourg, 2008.

36. Declaración de Riga: Declaración de los Ministros en Relación con el Programa Urbano de la UE; Ministros de la UE responsables de la Cohesión Territorial y Asuntos Urbanos: Riga, Letonia, 2015.

37. Declaración de Cork 2. 0 "Una Vida Mejor en el Medio Rural"; Oficina de Publicaciones de la Unión Europea: Luxembourg, 2016.

38. Informal Meeting of EU Minister Responsible for Urban Matters in Amsterdam Urban Agenda for the European Union; European Union: Amsterdam, The Netherlands, 2016.

39. Estudio Territorial de Extremadura II. Dirección General de Urbanismo, Agricultra y Ordenación del Territorio. Available online: https://www.aragon.es (accessed on 20 July 2020).

40. Plan Estratégico de apoyo al Medio Rural. Available online: http://www.juntaex.es/filescms/ con03/uploaded_files/SectoresTematicos/DesarrolloRural/DiversificacionYDesarrolloRural/ PlanEstrategicoDeApoyoAlMedioRuralEnExtremadura.pdf (accessed on 20 July 2020).

41. Reto Demográfico y Equilibrio Territorial en Extremadura; Consejo Económico y Social de Extremadura y Junta de Extremadura: Mérida, Spain, 2019.

42. Comunidad Autónoma de Extremadura. Ley 11/2018, de 21 de diciembre, de "Ordenación Territorial y Urbanística Sostenible de Extremadura". In BOE, $n^{\circ}$ 35, de 9 de Febrero de 2019; Boletín Oficial del Estado: Madrid, Spain, 2019.

43. Pillet Capdepón, F. La planificación urbanística y estratégica y su relación con la valoración catastral en España. Boletín De La AGE 2010, 54, 323-333.

44. Berdegué, J.A.; Meynard, M.F. Las Ciudades en el Desarrollo Territorial Rural; RIMISP-Centro Latinoamericano para el Desarrollo Rural: Santiago, Chile, 2012.

45. Velázquez, J.M.; Estebaranz, A. Introduction of Sustainable Urban Mobility Plans (SUMP) -Implantación de los Planes de Movilidad Urbana Sostenible; Federación Española de Municipios y Provincias (FEMP) and ISOIN S. L.: Madrid, Spain, 2011.

46. Precedo, A. La Red Urbana; Editorial Síntesis: Madrid, Spain, 1988.

47. Sánchez Zabala, R. Jerarquía y red urbana en Extremadura: Aplicación de la técnica del Análisis Factorial. Norba. Rev. De Geogr. 1989, 8-9.

48. Arenal-Clave, A.T. El Sistema de Ciudades de Extremadura; Dirección General de Urbanismo, Consejería de Vivienda, Urbanismo y Transporte; Junta de Extremadura: Mérida, Spain, 2001. 
49. Atlas Socieconómico de Extremadura; Instituto de Estadística de Extremadura; Junta de Extremadura: Mérida, Spain, 2019.

50. Nieto Masot, A.; Cárdenas Alonso, G.; Engelmo Moriche, Á. Spatial Analysis of the Rural-Urban Structure of the Spanish Municipalities. ISPRS Int. J. Geo-Inf. 2020, 9, 213. [CrossRef]

51. Cardozo, O.D.; Gómez, E.L.; Parras, M.A. Teoría de grafos y sistemas de información geográfica aplicados al transporte público de pasajeros en Resistencia (Argentina). Rev. Transp. Y Territ. 2009, 89-111.

52. Menédez, A. Una breve introducción a la teoría de grafos. Suma 1998, 28, 11-26.

53. Gómez Delgado, M.; Bosque Sendra, J.B. Cálculo de rutas óptimas para el transporte de residuos tóxicos y peligrosos. Geofocus. Rev. Int. De Cienc. Y Tecnol. De La Inf. Geográfica 2001, 49-75.

54. Nieto Masot, A.; Engelmo-Moriche, Á.; Cárdenas-Alonso, G. La distribución territorial de recursos sanitarios y socio-sanitarios públicos para población mayor en Extremadura. Rev. De Estud. Andal. 2019, 37, 141-160.

55. Nieto Masot, A.; Cárdenas Alonso, G. Research on the accessibility to health and educational services in the rural areas in Extremadura. Eur. Ctry. 2015, 7, 57-67. [CrossRef]

56. Reig, E.; Gisbert, F.J.; Cantarino, I. Construcción de una tipología rural/urbana para los municipios españoles. Investig. Reg. 2016, 35, 151-173.

57. Estebanez Alvarez, J.y.; Martin Lou, A. Determinación cuantitativa de la centralidad de los asentamientos. Geogr. Cons. Super. De Investig. Científicas 1973, 4, 313-331.

58. Oliveira Martins, J. Assessing and Governing Rural-Urban Interactions. In Sustainable Urban Rural Partnership European Conference; Regional Development Policy Division; GOV OECD: Metz, France, 2012.

59. Ortega Delgado, M. La ciudad y los sistemas urbanos desde una visión territorial. Urban. Revista del Departamento de Urbanística y Ordenación del Territorio de la Escuela Técnica Superior de Arquitectur; Universidad Politécnica de Madrid: Madrid, Spain, 2003; No. 8.

(C) 2020 by the authors. Licensee MDPI, Basel, Switzerland. This article is an open access article distributed under the terms and conditions of the Creative Commons Attribution (CC BY) license (http://creativecommons.org/licenses/by/4.0/). 